BMJ Open

Ophthalmology

\title{
Digital eye strain: prevalence, measurement and amelioration
}

\author{
Amy L Sheppard, James S Wolffsohn
}

To cite: Sheppard AL, Wolffsohn JS. Digital eye strain: prevalence, measurement and amelioration. BMJ Open Ophthalmology 2018;3:e000146. doi:10.1136/ bmjophth-2018-000146

Received 12 January 2018 Revised 16 March 2018 Accepted 27 March 2018
Check for updates

School of Life and Health Sciences, Aston University, Birmingham, UK

Correspondence to Dr Amy L Sheppard; A. SHEPPARD@aston.ac.uk

\section{ABSTRACT}

Digital device usage has increased substantially in recent years across all age groups, so that extensive daily use for both social and professional purposes is now normal. Digital eye strain (DES), also known as computer vision syndrome, encompasses a range of ocular and visual symptoms, and estimates suggest its prevalence may be $50 \%$ or more among computer users. Symptoms fall into two main categories: those linked to accommodative or binocular vision stress, and external symptoms linked to dry eye. Although symptoms are typically transient, they may be frequent and persistent, and have an economic impact when vocational computer users are affected. DES may be identified and measured using one of several available questionnaires, or objective evaluations of parameters such as critical flicker-fusion frequency, blink rate and completeness, accommodative function and pupil characteristics may be used to provide indices of visual fatigue. Correlations between objective and subjective measures are not always apparent. A range of management approaches exist for DES including correction of refractive error and/or presbyopia, management of dry eye, incorporating regular screen breaks and consideration of vergence and accommodative problems. Recently, several authors have explored the putative role of blue light-filtering spectacle lenses on treating DES, with mixed results. Given the high prevalence of DES and nearuniversal use of digital devices, it is essential that eye care practitioners are able to provide advice and management options based on quality research evidence.

\section{INTRODUCTION}

Computer vision syndrome (CVS) is characterised by a range of eye and vision-related symptoms and has been a recognised health problem for over 20 years. ${ }^{12}$ The terms visual fatigue (VF) and digital eye strain (DES) are also used for the condition, reflecting the variety of digital devices linked to potential problems. These expressions may be more appropriate for communication with patients and the public, who may not consider devices such as tablets and smartphones to be computers. ${ }^{3}$ Given the massive growth in digital device usage in recent years, many millions of individuals of all ages are at risk of DES. While symptoms are usually transient, the condition can cause significant, frequent, discomfort for sufferers and may have substantial economic consequences when vocational computer users are affected through increased errors and more frequent breaks. $^{4}$

The following review considers new findings in this active field. Recent data and information on usage of digital devices, assessment techniques and management of the condition are presented. Furthermore, in addition to the more commonly described subjective techniques (ie, questionnaires) that are used in this area of research, objectively determined indicators of DES are considered.

\section{Use of digital devices}

Across all age groups in developed nations, engagement with digital devices has increased substantially in recent years, particularly in the field of mobile media. ${ }^{5}$ A multination European study including England, reported that by 3 years of age, $68 \%$ of children regularly use a computer and $54 \%$ undertake online activities. ${ }^{6}$ In 2016, it was estimated that UK adults typically spend 4 hours $45 \mathrm{~min}$ per day using digital media, ${ }^{7}$ with a similar pattern in the USA, where approximately two-thirds of adults aged 30-49 years spend five or more hours on digital devices. ${ }^{8}$

In older age groups, use of technology is growing rapidly (figure 1) between 2011 and 2017, the proportion of the population classed as 'recent internet users' (within the last 3 months) more than doubled in the 75 years and over age group, and increased from $52.0 \%$ to $77.5 \%$ in those aged $65-74$ years. $^{9}$ Recent US data indicate that $37 \%$ of adults aged 60 years and over spend five or more hours per day using digital devices, and this age group prefers using laptops and desktops for browsing the internet, whereas younger adults are more likely to use smartphones for this purpose. ${ }^{8}$ Use of social media and multitasking is particularly prominent among younger adults with $87 \%$ of individuals aged 20-29years reporting use of two or more digital devices simultaneously. ${ }^{8}$

\section{SYMPTOMS AND PREVALENCE}

According to the American Optometric Association, ${ }^{10}$ the most common symptoms 


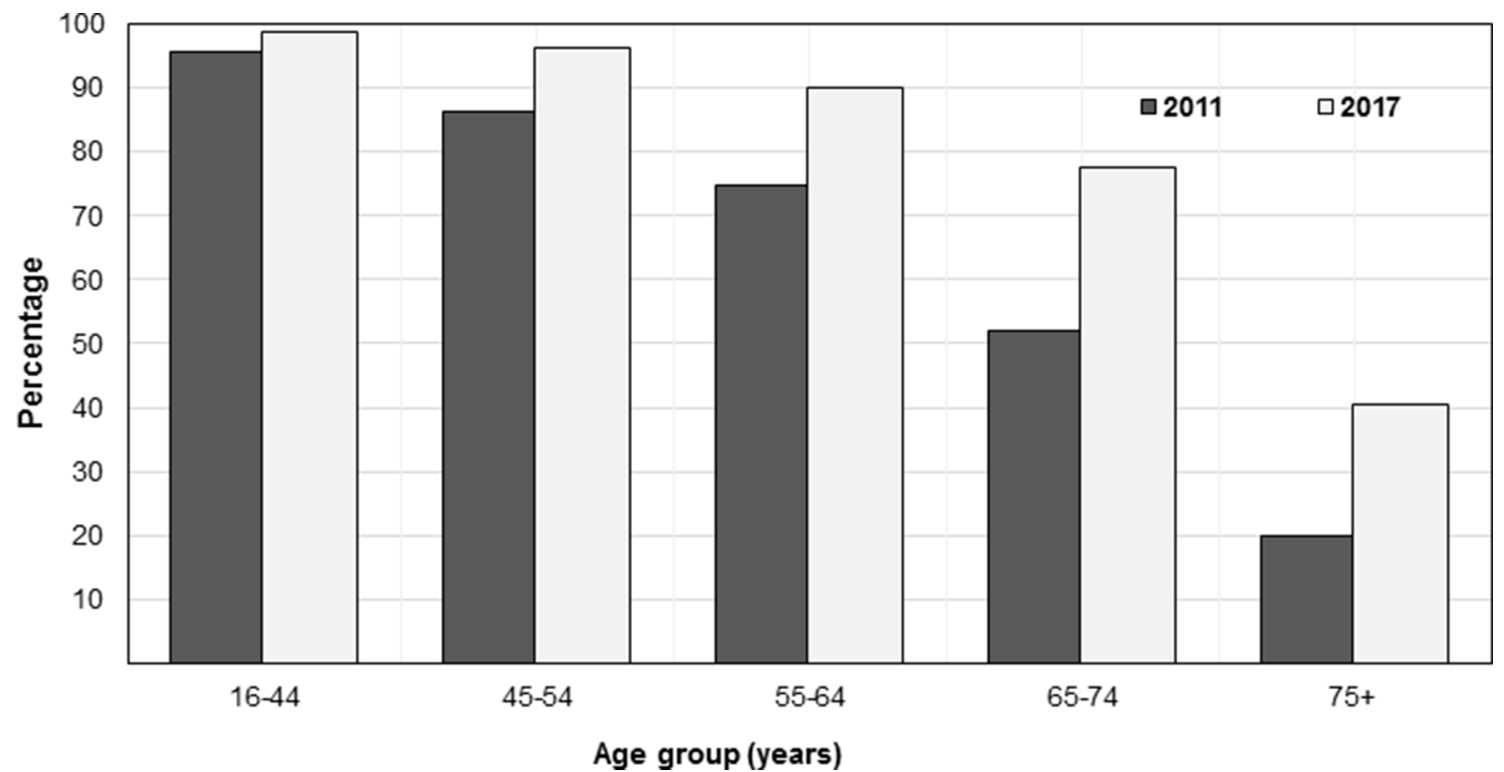

Figure 1 Recent internet use (within the last 3 months) among UK adults in 2011 and 2017. Data obtained from the Office for National Statistics. ${ }^{9}$

associated with DES are eyestrain, headaches, blurred vision, dry eyes and pain in the neck and shoulders. Asthenopia is the formal term for eye strain, for which two distinct mechanisms and sets of symptoms were described by Sheedy et al. ${ }^{11}$ External symptoms of burning, irritation and tearing and dryness were noted to be closely related to dry eye, while internal symptoms of strain, ache and headache behind the eyes were linked to accommodative and/or binocular vision stress. Similarly, Portello et $a l^{12}$ also identified a clear split of computer-related symptoms into two categories: those associated with accommodation (namely, blurred vision at near, blurred distance vision after computer use and difficulty refocusing from one distance to another) and those that seemed linked to dry eye (irritated/burning eyes, dry eyes, eyestrain, headache, tired eyes, sensitivity to bright lights and eye discomfort).

The prevalence of DES has received attention in the scientific literature for over 20 years. Gauging prevalence is challenging due to the wide variety of usage conditions (both vocationally and socially) and substantial changes in these over time, along with the range of methodologies that have been applied to identify sufferers. Recent data, representative of contemporary devices and usage patterns, indicate that DES is a very common problem affecting many millions of individuals. The 2016 Digital Eye Strain report, ${ }^{8}$ which included survey responses from over 10000 US adults, identified an overall self-reported symptom prevalence of $65 \%$, with females more commonly affected than males (69\% vs $60 \%$ prevalence). DES was reported more frequently by individuals who used two or more devices simultaneously, compared with those using just one device at a time, with prevalences of $75 \%$ and $53 \%$, respectively. The finding of greater computer-related symptoms in females was in agreement with 2012 findings among a cohort of 520 office workers in New York City ${ }^{12}$ and may be linked to gender differences in dry eye prevalence. ${ }^{1314}$ For 10 defined symptoms, Portello et $a l^{12}$ documented that each symptom had been experienced by over $50 \%$ of respondents at least 'some of the time' during computer use within the last week. As shown in table 1, each symptom was reported half of the time or more during computer use over the last week in $17.3 \%-39.8 \%$ of respondents, highlighting the potentially persistent and frequent nature of DES complaints.

Among 426 civil servants in Spain, the overall prevalence of DES (detected using a validated questionnaire)

Table 1 Percentage of respondents $(n=520$ New York City office workers) reporting symptoms during computer use at least half of the time over the last week. Data extracted from Portello et al ${ }^{12}$

Percentage of respondents reporting symptom at least half of

Symptom the time

\begin{tabular}{|c|c|}
\hline $\begin{array}{l}\text { Blurred vision while viewing the } \\
\text { computer }\end{array}$ & 17.3 \\
\hline $\begin{array}{l}\text { Blurred vision when looking in to } \\
\text { the distance }\end{array}$ & 23.4 \\
\hline $\begin{array}{l}\text { Difficulty or slowness in } \\
\text { refocusing my eyes from one } \\
\text { distance to another }\end{array}$ & 21.6 \\
\hline Irritated or burning eyes & 27.5 \\
\hline Dry eyes & 31.5 \\
\hline Eye strain & 30.6 \\
\hline Headache & 22.3 \\
\hline Tired eyes & 39.8 \\
\hline Sensitivity to bright lights & 26.3 \\
\hline Eye discomfort & 30.8 \\
\hline
\end{tabular}


was $53 \% .^{15}$ With six or more hours of computer use, contact lens wearers were more likely to be affected than non-wearers, with prevalences of $65 \%$ and $50 \%$, respectively. The finding was attributed to possible incomplete removal of superficial deposits with multipurpose lens care solutions and/or the mechanical interaction of silicone hydrogel lenses with the ocular surface. ${ }^{15}$

Considering dry eye disease (DED) specifically in computer users, a recent meta-analysis including data from 11365 individuals estimated an overall prevalence of $49.5 \%$, ranging from $9.5 \%$ to $87.5 \%$. ${ }^{14}$ While these values appear higher than the 5\%-33\% DED prevalence observed in the general population, ${ }^{16}$ the heterogeneity of diagnostic criteria for DED used in studies to date mean that the overall figure has limited value. Standardised criteria for DED diagnosis and universal implementation would enable more robust estimates of the prevalence of the condition among computer users. The recent Tear Film and Ocular Surface Society Dry Eye Workshop II report included detailed recommendations for diagnostic methodology. ${ }^{17}$ Key proposals were symptom screening with either the Ocular Surface Disease Index (OSDI) or Dry Eye Questionnaire (DEQ-5) instruments, followed by objective clinical tests in DED suspects, including breakup time (preferably non-invasive), osmolarity and ocular surface staining with fluorescein and lissamine green. ${ }^{17}$

The problem of dry eye linked to digital device usage is not limited to adults. Recent studies based in South Korea have indicated that longer daily durations of both visual display terminal (VDT) ${ }^{18}$ and smartphone ${ }^{18} 19$ use are risk factors for DED in children. Cessation of smartphone use for a 4-week period in children with DED aged 7-12 years resulted in significant improvements in non-invasive tear breakup time, punctate epithelial erosion and OSDI scores, with all affected children no longer being classified as DED sufferers at the end of the abstinence period. ${ }^{19}$ The prevalence of DES in paediatric populations has received little attention in the literature to date, although a recent meta-analysis of available data linked to asthenopia in children ${ }^{20}$ reported a pooled prevalence of $19.7 \%$. A scarcity of data in this field was highlighted, along with difficulties comparing studies due to the variation in methods. Given that asthenopia may impact on learning and school performance, and children are increasingly heavy users of digital devices, further research is needed to gauge the prevalence and consequences of the condition in children.

\section{MEASURING DES}

\section{Subjective methods}

A variety of instruments have been used to identify DES sufferers and grade the severity of complaints. A 10-item questionnaire created by Hayes $e t a l^{21}$ has been deployed in several subsequent studies ${ }^{12} 22$ and relates to the level of ocular discomfort experienced from the symptoms listed in table 1, enabling calculation of a total symptom score. The six-item Visual Fatigue Scale requires users to respond using a Likert scale to difficulties in seeing, strange feeling around the eyes, eyes feeling tired, feeling numb, having a headache and feeling dizzy looking at the screen. It has been applied to study symptoms following the use of e-readers, indicating that reading from liquid crystal display (LCD) screens (eg, tablet devices) triggers more subjectively reported $\mathrm{VF}$ than reading from paper copies or e-ink displays. ${ }^{23}$

The Rasch-based Computer-Vision Symptom Scale $(\text { CVSS17 })^{24}$ was developed in Spanish to measure visual and ocular symptoms in computer users. An English version of the questionnaire may be obtained, although currently, normal CVSS values dependent on race and other factors are unknown. Seguí and colleagues ${ }^{25}$ developed the first validated questionnaire in English to evaluate DES in the workplace. The self-administered Computer Vision Syndrome Questionnaire (CVS-Q) requires users to indicate the frequency and intensity of 16 symptoms experienced during computer use, allowing a single symptom severity score (CVS score) to be deduced, where six points or more is considered diagnostic of the condition. The CVS-Q was used to analyse CVS in contact lens wearers. ${ }^{15}$ Questionnaires with verified validity and reliability are useful tools to incorporate into regular patient care and clinical trials linked to ocular and visual health of workers engaged in computer use. Subjective questionnaires have also been used to provide additional validation for objective measures of $\mathrm{VF}^{26}$ which are considered in the following section.

\section{Objective evaluation}

Although DES affects a huge number of individuals, its precise physiological basis remains unclear. An array of measures of visual function have been used to provide indices of VF: accommodation parameters have received a significant amount of research attention given the accommodative nature of several DES symptoms, while critical flicker-fusion frequency (CFF) and blinking characteristics have been used regularly in recent DES research.

\section{Critical flicker-fusion frequency}

$\mathrm{CFF}$ is a recognised metric indicative of fatigue and mental workload $^{27}$ and is the frequency at which a flickering light is indistinguishable from a steady, non-flickering light. A decline in this parameter has been attributed to reduced activity of the retina and/or optic nerve. ${ }^{28} \mathrm{Nega-}$ tive changes in CFF following a prolonged computer task were observed to correspond with certain subjective ocular complaints (pain in/around the eyes, eyes feeling heavy and itchy eyes) in a recent study on the effects of short wavelength-blocking spectacles ${ }^{29}$ although not all studies using the measure have established a correlation between worsening of CFF and increased symptoms. ${ }^{30} 31$ CFF may be influenced by task time, with Chi and $\operatorname{Lin}^{26}$ reporting a significant increase in the sensitivity of this parameter to load differences when task duration was extended. For a $0.4 \mathrm{~Hz}$ tracking task, mean post-task CFF 
reductions were $1.2 \pm 1.5 \mathrm{~Hz}$ and $2.2 \pm 0.7 \mathrm{~Hz}$ for $20 \mathrm{~min}$ and 60 min durations, respectively. ${ }^{26}$

\section{Blinking and squinting}

Blinking aids maintenance of a normal ocular surface, with most blinks instigating a cycle of secretion, dispersal, evaporation and drainage of tears. ${ }^{32}$ Reduced blink rate with computer use has been observed in numerous studies $^{33-35}$ and may be relevant to dry eye symptoms that frequently occur with DES. Reductions in blink rate may be substantial, for example, Patel $e t a l^{33}$ reported a mean rate of $18.4 \mathrm{blinks} / \mathrm{min}$ before computer use, decreasing to 3.6 blinks/min during operation, while Tsubota and Nakamori ${ }^{35}$ observed a mean rate of 22 blinks/min among office workers under relaxed conditions, reducing to seven blinks/min when viewing an electronic display.

Sheedy $e t a l^{36}$ hypothesised that reduced blink rate may be a consequence of involuntary squinting under symptom-producing conditions, with squinting contributing to asthenopia. Two potential benefits arise from squinting: improvement in visual acuity with refractive error and decreasing retinal illumination in the presence of a glare source in the superior visual field. ${ }^{37}$ The voluntary squint response, measured using electromyography (EMG) of the orbicularis oculi, influences blink rate significantly, with greater squint levels causing more substantial reduction of blink rate. ${ }^{36}$ A later study, ${ }^{38}$ exposing participants to various asthenopic conditions during computer use including small font size, low contrast, induced refractive error and glare revealed that conditions that may be improved by squinting (refractive error and glare) showed an increased EMG response from the orbicularis oculi along with an increase in blink rate, while those that would not benefit from squinting (small font size and low contrast) showed no significant EMG response but a reduction in blink rate. Blink inhibition may arise from high cognitive demand or low-legibility conditions necessitating a lengthening of fixation duration and allowing increased time to acquire visual information.

Increased cognitive demand (eg, reading more challenging material) exacerbates the effect of visual stressors such as low contrast or refractive error. ${ }^{39}$ Rosenfield et a $t^{40}$ exposed 16 teenage subjects to texts of two distinct levels of cognitive demand, both on a modern tablet computer and hard copy printed versions. Changing the cognitive demand had a greater impact on blink rate than presentation format. Mean blink rates for the low demand task were 8.34 and 9.06 blinks/min for the tablet and paper presentations, respectively, reducing significantly to 7.43 and $6.67 \mathrm{blinks} / \mathrm{min}$, respectively, for the high demand task. It is possible that technological improvements in digital displays mean that they are more similar to printed materials, so the substantial reductions in blink rate with computer use reported in older studies may not be indicative of modern effects.

Although reduced blink rate may be a less pertinent issue now, many individuals continue to experience signs and symptoms of dry eye associated with digital device
Table 2 Blink rate and proportion of incomplete blinks for various hard copy text and electronic reading conditions, as reported by Argilés et al ${ }^{43}$

\begin{tabular}{lcc}
\hline & $\begin{array}{l}\text { Spontaneous } \\
\text { blink rate, blinks/ } \\
\text { min Median (IQR) }\end{array}$ & $\begin{array}{l}\text { \% Incomplete } \\
\text { blinks } \\
\text { Median (IQR) }\end{array}$ \\
\hline $\begin{array}{l}\text { Experimental condition } \\
\text { at } 2 \mathrm{~m}\end{array}$ & $14.5(29.5)$ \\
$\begin{array}{l}\text { Tablet: reading at } 45^{\circ} \\
\text { angle at } 40 \mathrm{~cm}\end{array}$ & $6(11)$ & $14.5(28.5)$ \\
$\begin{array}{l}\text { PC: reading at } 100 \% \\
\text { magnification at } 60 \mathrm{~cm}\end{array}$ & $6.5(11)$ & $9(20)$ \\
$\begin{array}{l}\text { PC: reading at } 300 \% \\
\text { magnification at } 60 \mathrm{~cm}\end{array}$ & $11.5(11)$ & $13.5(25.8)$ \\
$\begin{array}{l}\text { Text: pasted on switched } \\
\text { off display at } 60 \mathrm{~cm}\end{array}$ & $7(12)$ & $0(16.3)$ \\
$\begin{array}{l}\text { Text: on book rest at } 45^{\circ} \\
\text { angle at } 40 \mathrm{~cm}\end{array}$ & $5(10)$ & $0(22.8)$ \\
$\begin{array}{l}\text { Text: read aloud at } 45^{\circ} \\
\text { angle at } 40 \mathrm{~cm}\end{array}$ & $4(9)$ & \\
\hline
\end{tabular}

usage. Incomplete blinking, where the upper eyelid does not cover the entire corneal surface, may be more relevant to dry eye than blink rate as tear film stability can be maintained with a reduced blink rate, providing that most blinks are complete. ${ }^{41}$ Incomplete blinking can result in increased evaporation and tear film break up due to reduced tear film thickness in the inferior corneal region. ${ }^{42}$ Argilés et al ${ }^{43}$ observed a reduction in blink rate during reading tasks on tablet and computer displays (table 2), as well as hard copy text. However, reading from a hard copy was associated with a significantly lower proportion of incomplete blinks $(0 \%-5 \%)$ compared with reading from a tablet (14.5\%), expanded computer display $(13.5 \%)$ or electronic reading (9\%; see table 2$)$. The specific influence of digital devices on incomplete blinks is unclear, and further research is needed to address this issue, along with the possible benefits of blink training.

\section{Accommodative effects}

To perform near tasks comfortably, pre-presbyopes must be able to accommodate rapidly and smoothly and maintain an accurate response. ${ }^{4}$ The lag of accommodation when viewing computer displays has been studied by several authors. Wick and Morse ${ }^{45}$ reported from a small sample of young adults that lag (measured with an openview autorefractor) was approximately $0.33 \mathrm{D}$ higher in 4 of 5 participants when reading from a VDT compared with printed material, although Penisten et $a l^{46}$ found similar lags (by dynamic retinoscopy) in printed and VDT conditions. More recently, Collier and Rosenfield ${ }^{47}$ reported a stable mean lag of approximately $0.93 \mathrm{D}$ among 20 adults during a $30 \mathrm{~min}$ laptop-based task. Notably, no differences in static accommodation responses were identified between the most symptomatic and least symptomatic 
groups, although the task duration may not characterise heavy usage patterns of digital devices.

The accommodative response to a stationary near target exhibits microfluctuations-small temporal variations in power of up to $0.25 \mathrm{D},{ }^{48} 49$ comprising a low frequency component (LFC) of $<0.6 \mathrm{~Hz}$ and a high frequency component (HFC) of $1.0-2.3 \mathrm{~Hz}^{50}$ The HFC derives from arterial pulse effects, while the LFC is believed to be important in the maintenance of steady-state accommodation. Thus, examination of the microfluctuations may give an insight into the accuracy of the negative feedback control system of the accommodative response to any stimuli, ${ }^{51}$ including digital screens. Iwasaki and Kurimoto $^{52}$ reported increased microfluctuations after VDT use, but not after paper work. However, their analysis of microfluctuations (from $0 \mathrm{~Hz}$ to $1.5 \mathrm{~Hz}$ ) did not permit differentiation between the LFC and HFC. Gray et $a l^{51}$ explored microfluctuations in five asymptomatic young adults performing a $20 \mathrm{~min}$ task with five different displays, including hard copy, cathode ray tube and LCD. Overall, no change in the LFC or HFC was observed as the task progressed, and no difference between display types was reported. One subject did display a significant increase in LFC power at the conclusion of tasks, particularly for hard copy and electroluminescent panel display. Analysis of microfluctuations could prove more valuable in symptomatic individuals, providing information on subtle changes in the accommodative response with different display conditions, although this parameter has been studied relatively little in relation to DES, possibly due to the highly specialised laboratory requirements.

Accommodative facility, the ability to make rapid changes in accommodation response, may be pertinent to computer use, as switching fixation from the screen to other material or into the distance occurs frequently. Among 153 symptomatic computer users examined at a specialist clinic, poor accommodative facility was the most common diagnosis, detected in 31 (20.3\%) patients. ${ }^{53}$ Rosenfield $e t a l^{54}$ examined accommodative facility in 22 young, visually normal subjects, before and after a $25 \mathrm{~min}$ desktop computer task. No significant change in monocular facility was observed, while binocular values improved somewhat post-task. Furthermore, as no relationship was established between symptoms and accommodative facility, the conclusion that poor accommodative facility was not linked to ocular fatigue was made. Whether these results are broadly applicable to sufferers of DES is questionable as these young, visually normal subjects reported relatively low symptom scores, and the task duration may not have been sufficient to result in significant changes in accommodative parameters. Chi and $\mathrm{Lin}^{26}$ highlighted improved sensitivity of several parameters linked to VF, including accommodation power and visual acuity, when task duration was extended from $20 \mathrm{~min}$ to $60 \mathrm{~min}$.

\section{Pupillary light reflex and size}

Along with accommodation and convergence, the pupil response is the third component of the near triad.
Changes in pupillary characteristics and response have been explored as potential indicators of VF. Monitoring pupil diameter within-task has led to the hypothesis that an increase in pupil size indicates VF, due to detrimental effects on depth of focus. ${ }^{26}$ Task type has been shown to influence changes in pupil diameter, with more demanding tasks, such as faster on-screen presentation of figures ${ }^{55}$ and tracking (rather than reading or monitoring), causing greater increases in pupil diameter, although only a weak correlation with subjective complaints has been established. ${ }^{26} \mathrm{Gray}$ et $a l^{51}$ reported a significant overall increase in pupil size during $20 \mathrm{~min}$ tasks on various displays, with the effect observed in 3 of 5 visually normal subjects.

After effects have been reported in up to $33 \%$ of individuals following intense near work, ${ }^{56}$ where the pupil may retain a somewhat constricted state after task completion. Saito et $a \bar{l}^{\overline{7}}$ noted reduced pupil diameter and increased amplitude of pupillary reflexes following a prolonged VDT task, postulating that spasms of the sphincter pupillae and ciliary muscle may be responsible. Dynamic recording of pupil size and refractive error using an open-view autorefractor as described by Gray et $a p^{11}$ could facilitate analysis of post-task pupil recovery when after effects are present while also enabling study of within task accommodative response (accuracy) and pupil size.

\section{Aggravating factors and management of DES}

Numerous factors are believed to contribute to DES, and it has been asserted that a combination of symptom-inducing factors may increase the magnitude of symptoms. ${ }^{58}$ Therapeutic interventions may be broadly separated into treatment of dry eye, correction of refractive error and management of accommodation and vergence anomalies. The use of commercially available blue-blocking spectacle lenses as a possible treatment for DES has also attracted some interest recently.

\section{Management of dry eye}

Dry eye is considered a significant aetiology of DES, with factors such as altered blinking characteristics, environmental influences and gaze angle considered relevant to dryness with digital device use. Office environments commonly feature low humidity, ventilation fans, air conditioning and airborne dust/toner particles, which may promote corneal drying. ${ }^{59}$ Desktop computer screens are frequently viewed in horizontal gaze, thus the palpebral aperture is wider than for conventional reading tasks (or laptop/tabletuse), which are usually performed in downgaze. Consequently, a larger ocular surface area is exposed to the effects of tear film evaporation. ${ }^{589}$

Use of lubricating eye drops has been shown to reduce symptoms such as tiredness, dryness and difficulty focusing during sustained computer use, ${ }^{60}$ although complete resolution of symptoms may not occur. ${ }^{61} \mathrm{~A}$ randomised controlled study of 478 symptomatic computer users (>3 hours per day) demonstrated a beneficial effect of 
dietary supplementation with omega-3 fatty acids on dry eye signs and symptoms, with $70 \%$ in the treatment group being symptom free after 3 months. ${ }^{62}$

Given the impact of digital device usage on blinking characteristics, blink training may be helpful in the management of DES symptoms linked to dry eye. Increasing blink rate through use of an audible prompt signal every $4 \mathrm{~s}$ during a computer task was not found to alter symptom scores, ${ }^{63}$ although blink efficiency exercises to reduce the number of incomplete blinks may be more appropriate given the link between screen use and incomplete blinking.

\section{Refractive error and presbyopia}

Correction of refractive error (notably astigmatism) and presbyopia is accepted as an important intervention in DES sufferers. Double-masked, randomised studies have established that even $0.50-1.00 \mathrm{D}$ of uncorrected simulated astigmatism impacts negatively on subjective visual comfort, ${ }^{64}{ }^{65}$ while $1.00-2.00 \mathrm{D}$ of induced or natural astigmatic error may increase task errors by up to $370 \%$ and reduce productivity of computer workers substantially. ${ }^{4}$ Uncorrected astigmatism may be a particular issue among presbyopic patients using off-the-shelf reading spectacles and contact lens wearers with undercorrected or uncorrected cylindrical errors.

The variety of working distances involved in using different digital devices can prove problematic for individuals requiring a near vision add. Small fonts are common on smartphones due to reduced screen size, and a mean working distance of $32.2 \mathrm{~cm}$ was established in adults undertaking a web-based smartphone task, ${ }^{66}$ which may reduce during prolonged viewing. ${ }^{67}$ Minimum viewing distances of $500-635 \mathrm{~mm}^{68}{ }^{69}$ have been recommended for computer monitors, while working distances of around $500 \mathrm{~mm},{ }^{70}$ or slightly less with increased age, ${ }^{71}$ are typical for e-readers. Consequently, a single near add may not provide adequate vision across the range of demand levels, meaning that multiple prescriptions or an occupational correction (eg, combining intermediate and near prescriptions) are required. Computer glasses, with progressive lenses designed to optimise vision in the intermediate and near regions, may reduce symptoms in presbyopic computer users to a greater extent than ergonomic intervention, ${ }^{72}$ while a 2004 study indicated that over a 12-month period, some designs of computer lenses provided greater overall satisfaction and improved subjective evaluation of area of clear vision than single vision spectacles. ${ }^{73}$

UK employees using display screen equipment (DSE) habitually as a significant part of their work are entitled to a sight test funded by their employer, along with spectacles specifically for screen use. ${ }^{74}$ According to College of Optometrists guidance on examining DSE/ computer users, ${ }^{75}$ practitioners should carry out a full eye examination to determine the cause of any visual problems associated with screen use, ask the patient to describe their workstation and environment and provide appropriate advice including ergonomic information. Despite near-universal use of digital devices, little is known regarding the interpretation of this guidance or how UK optometrists examine and advise patients regarding digital device usage, whether for professional or social purposes. To optimise patient care, increased education of optometrists and opticians regarding DES could be advantageous, given the high prevalence of the condition and continuing research developments in this active field, which may not be covered in detail in undergraduate training programmes.

\section{Accommodation and vergence anomalies}

Accommodative anomalies including poor facility and high lag may reduce visual comfort during nearwork, including computer use. Clinically, accommodative facility may be assessed with plus and minus sphere flipper lenses while the patient fixates a near target, counting the number of cycles 'cleared' in $1 \mathrm{~min}(\mathrm{cpm}) .{ }^{76}$ With the conventional $\pm 2.00 \mathrm{D}$ flippers at $40 \mathrm{~cm}, 11 \mathrm{cpm}$ has been described as the cut-off between symptomatic and asymptomatic adults, ${ }^{76}$ although more recent research suggests that facility testing should take into account the amplitude of accommodation of individual patients and be scaled accordingly. ${ }^{77} \mathrm{Lag}$ of accommodation is usually assessed by dynamic retinoscopy, with the distance-corrected patient fixating a near target. ${ }^{78}$ Ophthalmic practitioners should examine visual function at the distances at which screens are used by individual patients ${ }^{58}$ to ensure clear vision at appropriate task distances. The American Optometric Association promotes the 20-20-20 rule (a 20s break every $20 \mathrm{~min}$ to view a distant object at 20 feet) to alleviate DES. ${ }^{10}$ Frequent short breaks can relax accommodative and vergence responses, attenuating asthenopic symptoms without impairing productivity. ${ }^{790}$

Vergence dysfunctions include various motor disorders, for example, convergence insufficiency, decompensated heterophoria and poor vergence facility. Individuals with binocular vision problems experience greater visual symptoms with prolonged use of the eyes. ${ }^{81}{ }^{82}$ Vergence characteristics have been studied with respect to computer operation, producing mixed results. Watten and colleagues reported significant reductions in vergence ranges (assessed by increasing base in and base out prism power, until blur experienced) at the end of the working day, ${ }^{83}$ although other authors have shown no differences in vergence functions between individuals involved in computer work and those not using a computer. ${ }^{84-86}$ Rosenfield $e t a \tilde{l}^{54}$ reported no change in vergence facility (ability to make rapid changes in vergence response, using alternate presentation of base out and base in prism) following a 25 min computer task. Later work indicated no variation in associated phoria during computer work, although notably, the least symptomatic individuals had a mean associated phoria of $1.55 \Delta$ base in, that is, a slightly reduced vergence response. ${ }^{47}$ Around $20 \%$ of individuals were found to prefer an induced small exo-associated phoria compared with an ortho condition, 
suggesting that CVS may be ameliorated by stimulating an exo-associated phoria in some individuals. ${ }^{58}$

\section{Blue light}

Exposure to blue light $(400-500 \mathrm{~nm})$ can be harmful to the retina, particularly suprathreshold, acute doses, ${ }^{87} 88$ with peak light damage occurring around $440 \mathrm{~nm} .{ }^{89}$ Longer duration, less intense light exposure can also induce photochemical damage ${ }^{90}$ While some concern has been expressed regarding blue light emitted from digital screens, recent research indicated that the low levels of blue light from such devices do not represent a biohazard, even for long-term viewing. ${ }^{91}$ Newer forms of low energy lighting, including LEDs, emit less infrared radiation than their incandescent predecessors, but significantly more blue light leading to the suggestion that harmful cumulative exposures could occur. ${ }^{89} 92$ Theoretically, commercially available blue light-filtering spectacle lenses reduce phototoxicity by $10.6 \%-23.6 \%$, without degrading visual performance, and have thus been suggested as a supplementary aid for protecting the eyes against the blue light hazard. ${ }^{93}$

Light exposure is also the main factor involved in setting circadian rhythms. Melatonin hormone is released in dim light conditions and is involved in the physiological control of sleep. Its release from the pineal gland is controlled by a pathway originating from the intrinsically photosensitive retinal ganglion cells containing melanopsin, which has a peak sensitivity of approximately $482 \mathrm{~nm},{ }^{94}$ that is, longer wavelength blue-turquoise light. Exposure to short wavelength light (including digital devices) before bedtime can disrupt sleep patterns, ${ }^{95}{ }^{96}$ while use of short wavelength blocking spectacles in the evening can improve sleep duration and quality $^{9798}$ and reduce subjective alertness. ${ }^{99}$
Blue light emitted by digital devices has also been implicated as a cause of DES. Isono and colleagues ${ }^{100}$ reported reduced subjective complaints and smaller reductions in CFF in young adults when reading from a sepia background (reduced blue light contribution) compared with the conventional white background of a modern tablet device. Although cited by Lin $e t a l^{29}$ in their rationale for exploring the impact of blue-blocking spectacles on eye fatigue, the small sample size means that the results must be interpreted with caution.

Given both the putative link between the blue light emitted from modern digital devices and ocular complaints and the commercial availability of blue-filtering lenses for treatment of DES, several authors have explored the impact of blue light-reducing spectacles on symptoms and objective measures of $\mathrm{VF}^{29}{ }^{31} 101$ (see table 3). There is a lack of consensus in the findings of these studies, and a recent systematic review of the literature called for high-quality research, ideally in the form of randomised control trials, to address the health effects of blue blocking spectacle lenses. ${ }^{102}$

Cheng et $a l^{101}$ showed no improvement in Schirmer test results when dry eye and non-dry eye participants used low-blocking, medium-blocking and high-blocking wraparound goggles but did report reduced symptoms with all levels of filter in patients with dry eye. Of note is the lack of a control lens in the study and potential placebo effect, while the wraparound style of goggles means that reduced tear film evaporation in addition to blue-light reduction may have impacted the results. Following a 2-hour computer task, Ide $e t a l^{31}$ reported a significantly greater reduction in CFF in participants wearing control lenses, compared with those with high or low blue-blocking properties, although no differences in

Table 3 Published studies to date that have examined the impact of blue light-filtering spectacles on DES

\begin{tabular}{|c|c|c|}
\hline Author and year & Participants and methods & Key findings \\
\hline Cheng et al, $2014^{101}$ & $\begin{array}{l}\mathrm{n}=20 \text { 'dry eye' participants with reduced Schirmer } \\
\text { test values. } \\
\mathrm{n}=20 \text { with normal Schirmer values. } \\
\text { Wraparound goggles with low-blocking, medium- } \\
\text { blocking and high-blocking properties worn for } \\
\text { computer work for } 1 \text { week each. Schirmer test and } \\
\text { subjective questionnaire completed after each week. }\end{array}$ & $\begin{array}{l}\text { No significant change in Schirmer test values for } \\
\text { any group or filter. } \\
\text { Dry eye participants showed a reduction in } \\
\text { ocular complaint scores with all filter levels. }\end{array}$ \\
\hline Ide et al, $2015^{31}$ & $\begin{array}{l}\mathrm{n}=33 \text { participants in three groups of } 11 \text {. Each group } \\
\text { wore either high-blocking, low- blocking or control } \\
\text { lenses. } \\
\text { Intensive 2-hour computer task completed, with CFF } \\
\text { and subjective complaints measured pretask and } \\
\text { post-task. }\end{array}$ & $\begin{array}{l}\text { Control group showed significant post-task } \\
\text { worsening of CFF compared with high-blocking } \\
\text { and low-blocking groups. } \\
\text { No difference in subjective complaints between } \\
\text { the three groups. }\end{array}$ \\
\hline Lin et al, $2017^{29}$ & $\begin{array}{l}\mathrm{n}=36 \text { participants in three groups of } 12 \text {. Each group } \\
\text { wore no blocking, low-blocking or high-blocking } \\
\text { spectacles for } 2 \text {-hour computer task. } \\
\text { CFF and questionnaire completed pretask and post- } \\
\text { task. }\end{array}$ & $\begin{array}{l}\text { Post-task reduction in CFF significantly less in } \\
\text { high block group. No difference in CFF change } \\
\text { between low-block and no block groups. } \\
\text { High-block group reported less pain around/ } \\
\text { insidethe eyes and less feelings of itchy eyes } \\
\text { post-task compared with other groups. }\end{array}$ \\
\hline
\end{tabular}

CFF, critical flicker-fusion frequency; DES, digital eyestrain. 
subjective questionnaires were observed between groups. More recently, Lin et $a t^{29}$ measured improved posttask CFF in subjects wearing high-blocking spectacles compared with low-block or no block lenses and reported that 3 of 15 symptoms (pain in/around the eyes, eyes feeling heavy and eyes feeling itchy) were lower in the high-blocking group, indicating that short-wavelength filtering spectacles may attenuate both some symptoms of DES and clinical CFF measurement. Notably, the high-blocking spectacles used had an obvious yellow colouration with the transmission spectrum indicating some filtering effect across a range visible wavelengths. Recent research in an animal model has demonstrated that exposure to violet visible light may suppress myopia progression ${ }^{103}$; if this finding translates to human eyes, there would be implications for use of short-wavelength blocking lenses in young people at risk of myopigenesis or progression.

Further to improving subjective comfort, management of DES among computer workers may confer significant economic advantages. The experience of symptoms can reduce work accuracy, ${ }^{104} 105$ extend the time required to complete tasks ${ }^{4}$ and necessitate more frequent breaks. ${ }^{12}$ Following a double-blind study, it was estimated that provision of spectacles to correct small refractive errors in pre-presbyopic employees would increase productivity by at least $2.5 \%,{ }^{4}$ indicating a favourable cost-to-benefit ratio of this intervention. Furthermore, the implementation of short, frequent breaks can enhance working efficiency, adequately compensating for time spent away from the screen. ${ }^{79} 106$

\section{CONCLUSIONS}

Usage of digital devices for work and social purposes, often for many hours each day, is now normal among individuals of all ages. While there are challenges in determining the prevalence of DES, levels of $50 \%$ or more have been reported in numerous published studies, indicating that a large proportion of the population are at risk, and may seek advice and/or treatment linked to the condition. Eye care professionals are well placed to advise on DES, with professional bodies such as the College of Optometrists (UK) and the American Optometric Association providing some guidance for practitioners. To provide optimum patient care related to the condition, it is essential that eye care practitioners are well informed regarding DES and the growing evidence base in this field.

DES symptoms may be split into those linked to dry eye (external symptoms), and internal symptoms related to ametropia, accommodation or vergence problems. Accommodative and/orvergence issues with computer use seem to be a consequence of demanding near work, rather than screen use per se. Nevertheless, such symptoms still require management to promote comfortable viewing. Treatment of dry eye, even mild cases, may have a substantial influence on comfort with screen use.
Questionnaires are of value in evaluating DES as they are simple to implement and capture patient experiences, although validated instruments are rare. In evaluating putative DES treatments, questionnaires have frequently been used alongside objective measures linked to VF, although correlation between objective and subjective assessments has not always been apparent. Regardless of the type of intervention proposed (eg, management of dry eye, correction of refractive error, use of computer spectacles or blue-blocking lenses), persistent effects of treatment should be explored to indicate the true value of DES management options. With the high prevalence of DES and near-universal use of digital devices, it is paramount that the condition is considered by eye care practitioners, and treatment options are supported by available research evidence.

Contributors ALS was involved in planning and drafting the manuscript. JSW reviewed and revised the draft. Both authors read and approved the final manuscript.

Funding The authors have not declared a specific grant for this research from any funding agency in the public, commercial or not-for-profit sectors.

Competing interests None declared.

Patient consent Not required.

Provenance and peer review Not commissioned; externally peer reviewed.

Open Access This is an Open Access article distributed in accordance with the Creative Commons Attribution Non Commercial (CC BY-NC 4.0) license, which permits others to distribute, remix, adapt, build upon this work non-commercially, and license their derivative works on different terms, provided the original work is properly cited and the use is non-commercial. See: http://creativecommons.org/ licenses/by-nc/4.0/

(c) Article author(s) (or their employer(s) unless otherwise stated in the text of the article) 2018. All rights reserved. No commercial use is permitted unless otherwise expressly granted.

\section{REFERENCES}

1. Dain SJ, McCARTHY AK, Chan-Ling T. Symptoms in VDU Operators. Optometry and Vision Science 1988;65:162-7.

2. Costanza MA. Visual and ocular symptoms related to the use of video display terminals. J Behav Optom 1994;5:31-6.

3. Rosenfield M. Computer vision syndrome (A.K.A. digital eye strain). Optometry in Practice 2016;17:1-10.

4. Daum KM, Clore KA, Simms SS, et al. Productivity associated with visual status of computer users. Optometry 2004;75:33-47.

5. eMarketer. Digital set to take majority share in UK time spent with media in 2016. 2016. https://www.emarketer.com/Article/ Digital-Set-Take-Majority-Share-UK-Time-Spent-with-Media-2016/ 1013039 (accessed 10 Mar 2017).

6. Palaiologou I. Children under five and digital technologies: implications for early years pedagogy. European Early Childhood Education Research Journal 2016;24:5-24.

7. eMarketer. Mobile takes majority share of UK time with digital media. 2016. https://www.emarketer.com/Article/Mobile-TakesMajority-Share-of-UK-Time-with-Digital-Media/1014676 (accessed 10 Aug 2017).

8. The Vision Council. Eyes overexposed: The digital device dilemma: digital eye strain report. 2016. https://www.thevisioncouncil.org/ content/digital-eye-strain (accessed 10 Mar 2018).

9. Office for National Statistics. Internet users in the UK 2017. 2017. https://www.ons.gov.uk/businessindustryandtrade/ itandinternetindustry/bulletins/internetusers/2017\#quality-andmethodology (accessed 8 Mar 2018).

10. American Optometric Association. Computer vision syndrome. 2017. https://www.aoa.org/patients-and-public/caring-for-yourvision/protecting-your-vision/computer-vision-syndrome?sso=y (accessed 8 Mar 2018).

11. Sheedy JE, Hayes JN, Engle J. Is all asthenopia the same? Optom Vis Sci 2003;80:732-9. 
12. Portello JK, Rosenfield M, Bababekova Y, et al. Computer-related visual symptoms in office workers. Ophthalmic and Physiological Optics 2012;32:375-82.

13. Guillon M, Maïssa C. Tear film evaporation--effect of age and gender. Cont Lens Anterior Eye 2010;33:171-5.

14. Courtin R, Pereira B, Naughton G, et al. Prevalence of dry eye disease in visual display terminal workers: a systematic review and meta-analysis. BMJ Open 2016;6:e009675.

15. Tauste A, Ronda E, Molina M-J, et al. Effect of contact lens use on computer vision syndrome. Ophthalmic and Physiological Optics 2016;36:112-9.

16. Subcommittee $\mathrm{E}$. The epidemiology of dry eye disease: report of the epidemiology subcommittee of the international dry eye workshop. Ocular Surface 2007;5:93-107.

17. Wolffsohn JS, Arita R, Chalmers R, et al. TFOS DEWS II diagnostic methodology report. Ocul Surf 2017;15:539-74.

18. Moon JH, Lee MY, Moon NJ. Association between video display terminal use and dry eye disease in school children. Journal of Pediatric Ophthalmology \& Strabismus 2014;51:87-92.

19. Moon JH, Kim KW, Moon NJ. Smartphone use is a risk factor for pediatric dry eye disease according to region and age: a case control study. BMC Ophthalmol 2016;16:188.

20. Vilela MAP, Pellanda LC, Fassa AG, et al. Prevalence of asthenopia in children: a systematic review with meta-analysis. $J$ Pediatr 2015;91:320-5.

21. Hayes JR, Sheedy JE, Stelmack JA, et al. Computer use, symptoms, and quality of life. Optom Vis Sci 2007;84:E739-56.

22. Chu $\mathrm{C}$, Rosenfield M, Portello JK, et al. A comparison of symptoms after viewing text on a computer screen and hardcopy. Ophthalmic and Physiological Optics 2011;31:29-32.

23. Benedetto S, Drai-Zerbib V, Pedrotti M, et al. E-readers and visual fatigue. PLoS One 2013;8:e83676.

24. González-Pérez M, Susi R, Antona B, et al. The computer-vision symptom scale (CVSS17): development and initial validation. Investigative Opthalmology \& Visual Science 2014;55:4504-11.

25. Seguí MdelM, Cabrero-García J, Crespo A, et al. A reliable and valid questionnaire was developed to measure computer vision syndrome at the workplace. J Clin Epidemiol 2015;68:662-73.

26. Chi C-F, Lin F-T. A comparison of seven visual fatigue assessment techniques in three data-acquisition VDT tasks. Hum Factors 1998;40:577-90.

27. Łuczak A, Sobolewski A. Longitudinal changes in critical flicker fusion frequency: an indicator of human workload. Ergonomics 2005:48:1770-92.

28. Iwasaki T, Akiya S. The significance of changes in CFF values during performance of a VDT-based visual task. In: Kumashiro M, Megaw ED, eds. Towards Human Work: solutions to problems in occupational health and safety. London: Taylor and Francis, 1991.

29. Lin JB, Gerratt BW, Bassi CJ, et al. Short-Wavelength light-blocking eyeglasses attenuate symptoms of eye fatigue. Investigative Opthalmology \& Visual Science 2017;58:442-7.

30. Maeda E, Yoshikawa T, Hayashi N, et al. Radiology reading-caused fatigue and measurement of eye strain with critical flicker fusion frequency. Jpn J Radiol 2011;29:483-7.

31. Ide T, Toda I, Miki E, et al. Effect of blue light-reducing eye glasses on critical flicker frequency. Asia Pac J Ophthalmol 2015;4:80-5.

32. Himebaugh NL, Begley CG, Bradley A, et al. Blinking and Tear Break-Up During Four Visual Tasks. Optometry and Vision Science 2009;86:E106-E114.

33. Patel S, Henderson R, Bradley L, et al. Effect of visual display unit use on blink rate and tear stability. Optometry and Vision Science 1991;68:888-92.

34. Freudenthaler N, Neuf H, Kadner G, et al. Characteristics of spontaneous eyeblink activity during video display terminal use in healthy volunteers. Graefes Arch Clin Exp Ophthalmol 2003;241:914-20.

35. Tsubota K, Nakamori K. Dry eyes and video display terminals. $N$ Engl J Med Overseas Ed 1993;328:584

36. Sheedy JE, Gowrisankaran S, Hayes JR. Blink rate decreases with eyelid squint. Optometry and Vision Science 2005;82:905-11.

37. Sheedy JE, Truong SD, HAYES andJR. What are the visual benefits of eyelid squinting? Optometry and Vision Science 2003;80:740-4.

38. Nahar NK, Sheedy JE, Hayes J, et al. Objective measurements of lower-level visual stress. Optometry and Vision Science 2007;84:620-9.

39. Gowrisankaran S, Nahar NK, Hayes JR, et al. Asthenopia and blink rate under visual and cognitive loads. Optometry and Vision Science 2012;89:97-104.

40. Rosenfield M, Jahan S, Nunez K, et al. Cognitive demand, digita screens and blink rate. Comput Human Behav 2015;51:403-6.
41. Hirota M, Uozato H, Kawamorita T, et al. Effect of incomplete blinking on tear film stability. Optometry and Vision Science 2013;90:650-7

42. McMonnies CW. Incomplete blinking: exposure keratopathy, lid wiper epitheliopathy, dry eye, refractive surgery, and dry contact lenses. Contact Lens and Anterior Eye 2007;30:37-51.

43. Argilés $\mathrm{M}$, Cardona $\mathrm{G}$, Pérez-Cabré $\mathrm{E}$, et al. Blink rate and incomplete blinks in six different controlled hard-copy and electronic reading conditions. Investigative Opthalmology \& Visual Science 2015;56:6679-85.

44. Wick B, Hall P. Relation among accommodative facility, lag, and amplitude in elementary school children. Optometry and Vision Science 1987;64:593-8.

45. Wick B, Morse S. Accommodative accuracy to video display monitors. Optometry and Vision Science 2002;79:218.

46. Penisten DK, Goss DA, Philpott G, et al. Comparisons of dynamic retinoscopy measurements with a print card, a video display terminal, and a PRIO® system tester as test targets. Optometry Journal of the American Optometric Association 2004;75:231-40.

47. Collier JD, Rosenfield M. Accommodation and convergence during sustained computer work. Optometry - Journal of the American Optometric Association 2011;82:434-40.

48. Collins $\mathrm{G}$. The electronic refractometer. Br J Physiol Opt 1937:1:30-40.

49. Campbell FW, Robson JG, Westheimer G. Fluctuations of accommodation under steady viewing conditions. J Physiol 1959:145:579-94.

50. Gray LS, Winn B, Gilmartin B. Effect of target luminance on microfluctuations of accommodation. Ophthalmic and Physiological Optics 1993;13:258-65.

51. Gray L, Gilmartin B, Winn B. Accommodation microfluctuations and pupil size during sustained viewing of visual display terminals. Ophthalmic and Physiological Optics 2000;20:5-10.

52. Iwasaki T, Kurimoto S. Objective evaluation of eye strain using measurements of accommodative oscillation. Ergonomics 1987;30:581-7.

53. Sheedy JE, Parsons SD. The video display terminal eye clinic: clinical report. Optometry and Vision Science 1990;67:622-6.

54. Rosenfield M, Gurevich R, Wickware E, et al. Computer vision syndrome: accommodative \& vergence facility. J Behav Optom 2010;21:119-22.

55. Nishiyama K. Ergonomic aspects of the health and safety of VDT work in Japan: a review. Ergonomics 1990;33:659-85.

56. Tsuchiya K, Ukai K, Ishikawa S. A quasistatic study of pupil and accommodation after-effects following near vision. Ophthalmic and Physiological Optics 1989;9:385-91.

57. Saito S, Sotoyama M, Saito S, et al. Physiological indices of visual fatigue due to VDT operation: pupillary reflexes and accommodative responses. Ind Health 1994;32:57-66.

58. Rosenfield M. Computer vision syndrome: a review of ocular causes and potential treatments. Ophthalmic and Physiological Optics 2011;31:502-15.

59. Blehm C, Vishnu S, Khattak A, et al. Computer vision syndrome: a review. Surv Ophthalmol 2005;50:253-62.

60. Acosta MC, Gallar J, Belmonte C. The influence of eye solutions on blinking and ocular comfort at rest and during work at video display terminals. Exp Eye Res 1999;68:663-9.

61. Guillon M, Maissa C, Pouliquen P, et al. Effect of povidone $2 \%$ preservative-free eyedrops on contact lens wearers with computer visual syndrome:. Eye Contact Lens 2004;30:34-9.

62. Bhargava R, Kumar P, Phogat $H$, et al. Oral omega-3 fatty acids treatment in computer vision syndrome related dry eye. Contact Lens and Anterior Eye 2015;38:206-10.

63. Portello JK, Rosenfield M, Chu CA. Blink rate, incomplete blinks and computer vision syndrome. Optometry and Vision Science 2013;90:482-7

64. Wiggins NP, Daum KM. Visual discomfort and astigmatic refractive errors in VDT use. J Am Optom Assoc 1991;62:680-4.

65. Wiggins NP, Daum KM, Snyder CA. Effects of residual astigmatism in contact lens wear on visual discomfort in VDT use. J Am Optom Assoc 1992;63:177-81.

66. Bababekova Y, Rosenfield M, Hue JE, et al. Font size and viewing distance of handheld smart phones. Optometry and Vision Science 2011;88:795-7.

67. Long J, Cheung R, Duong S, et al. Viewing distance and eyestrain symptoms with prolonged viewing of smartphones. Clinical and Experimental Optometry 2017;100:133-7.

68. German DIN 66234. Characteristic values for the adaptation of workstations with fluorescent screens to humans. German: German DIN Association, 1981. 
69. Ankum DR. Viewing distance at computer workstations. Workplace Ergonomics 1996;2:10-13.

70. Shieh K-K, Lee D-S. Preferred viewing distance and screen angle of electronic paper displays. Appl Ergon 2007;38:601-8.

71. Hc W. Electronic paper display preferred viewing distance and character size for different age groups. Ergonomics 2011;54:806-14.

72. Butzon SP, Sheedy JE, Nilsen E. The efficacy of computer glasses in reduction of computer worker symptoms. Optometry 2002;73:221-30.

73. Horgen G, Aarås A, Thoresen M. Will visual discomfort among visual display unit (VDU) users change in development when moving from single vision lenses to specially designed VDU progressive lenses? Optom Vis Sci 2004;81:341-9.

74. Health and Safety Executive. Working with Display Screen Equipment (DSE). 2013. http://www.hse.gov.uk/msd/dse/ (accessed 10 Mar 2018).

75. College of Optometrists. Examining patients who work with display screen equipment or computers. 2017. http://guidance.collegeoptometrists.org/home/ (accessed 10 Mar 2018).

76. Levine $\mathrm{S}$, et al. Clinical assessment of accommodative facility in symptomatic and asymptomatic individuals. J Am Optom Assoc 1985:56:286-90.

77. Yothers T, Wick B, Morse S. Clinical testing of accommodative facility: part II. Development of an amplitude-scaled test. Optometry 2002;73:91-102.

78. Locke LC, Somers W. A comparison study of dynamic retinoscopy techniques. Optometry and Vision Science 1989;66:540-4.

79. Galinsky T, Swanson N, Sauter S, et al. Supplementary breaks and stretching exercises for data entry operators: a follow-up field study. Am J Ind Med 2007:50:519-27.

80. Balci R, Aghazadeh F. The effect of work-rest schedules and type of task on the discomfort and performance of VDT users. Ergonomics 2003;46:455-65.

81. Sheedy JE, Saladin JJ. Association of symptoms with measures of oculomotor deficiencies. Optometry and Vision Science 1978;55:670-6.

82. Cohen Y, Segal O, Barkana Y, et al. Correlation between asthenopic symptoms and different measurements of convergence and reading comprehension and saccadic fixation eye movements. Optometry Journal of the American Optometric Association 2010;81:28-34.

83. Watten RG, Lie I, Birketvedt O. The influence of long-term visual near-work on accommodation and vergence: a field study. $J$ Hum Ergol 1994;23:27-39.

84. Yeow PT, Taylor SP. Effects of short-term VDT usage on visual functions. Optometry and Vision Science 1989;66:459-66.

85. Yeow PT, Taylor SP. Effects of long-term visual display terminal usage on visual functions. Optometry and Vision Science 1991;68:930-41.

86. Nyman KG, Knave BG, Voss M. Work with video display terminals among office employees. IV. Refraction, accommodation, convergence and binocular vision. Scand J Work Environ Health 1985;11:483-7.

87. HAM WT, Mueller HA, Sliney DH. Retinal sensitivity to damage from short wavelength light. Nature 1976;260:153-5.
88. Jaadane I, Boulenguez P, Chahory S, et al. Retinal damage induced by commercial light emitting diodes (LEDs). Free Radical Biology and Medicine 2015;84:373-84.

89. Marshall J. Light in man's environment. Eye 2016;30:211-4

90. Tosini G, Ferguson I, Tsubota K. Effects of blue light on the circadian system and eye physiology. Mol Vis 2016;22:61-72.

91. O'Hagan JB, Khazova M, Price LLA. Low-energy light bulbs, computers, tablets and the blue light hazard. Eye 2016;30:230-3.

92. Krigel $A$, Berdugo M, Picard E, et al. Light-induced retinal damage using different light sources, protocols and rat strains reveals LED phototoxicity. Neuroscience 2016;339:296-307.

93. Leung TW, Li RW-hong, Kee C-su. Blue-Light Filtering Spectacle Lenses: Optical and Clinical Performances. PLoS One 2017;12:e0169114.

94. Berson DM, Dunn FA, Takao M. Phototransduction by retinal ganglion cells that set the circadian clock. Science 2002;295:1070-3.

95. Touitou Y, Touitou D, Reinberg A. Disruption of adolescents' circadian clock: the vicious circle of media use, exposure to light at night, sleep loss and risk behaviors. J Physiol Paris 2016:110:467-79.

96. Cajochen C, Frey S, Anders D, et al. Evening exposure to a light-emitting diodes (LED)-backlit computer screen affects circadian physiology and cognitive performance. J Appl Physiol 2011;110:1432-8.

97. Ostrin LA, Abbott KS, Queener HM. Attenuation of short wavelengths alters sleep and the ipRGC pupil response. Ophthalmic and Physiological Optics 2017;37:440-50.

98. Ayaki M, Hattori A, Maruyama Y, et al. Protective effect of blue-light shield eyewear for adults against light pollution from self-luminous devices used at night. Chronobiol Int 2016;33:134-9.

99. van der Lely S, Frey S, Garbazza C, et al. Blue blocker glasses as a countermeasure for alerting effects of evening light-emitting diode screen exposure in male teenagers. Journal of Adolescent Health 2015;56:113-9.

100. Isono $\mathrm{H}$, Kumar $\mathrm{A}$, Kamimura $\mathrm{T}$, et al. The effect of blue light on visual fatigue when reading on LED-backlit tablet LCDs. Procedings of International Display Workshops 2013.

101. Cheng H-M, Chen S-T, Hsiang-Jui L, et al. Does blue light filter improve computer vision syndrome in patients with dry eye? Life Science Journal 2014;11:612-5.

102. Lawrenson JG, Hull CC, Downie LE. The effect of blue-light blocking spectacle lenses on visual performance, macular health and the sleep-wake cycle: a systematic review of the literature. Ophthalmic and Physiological Optics 2017;37:644-54.

103. Torii $\mathrm{H}$, Kurihara $\mathrm{T}$, Seko $\mathrm{Y}$, et al. Violet light exposure can be a preventive strategy against myopia progression. EBioMedicine 2017:15:210-9.

104. Wilkinson* RT, Robinshaw HM. Proof-reading: VDU and paper text compared for speed, accuracy and fatigue. Behav Inf Technol 1987;6:125-33

105. Wright $P$, Lickorish $A$. Proof-reading texts on screen and paper. Behav Inf Technol 1983;2:227-35.

106. McLean L, Tingley M, Scott RN, et al. Computer terminal work and the benefit of microbreaks. Appl Ergon 2001;32:225-37. 